\title{
Explaining the segmentation effect in learning from animations: The role of pausing and temporal cueing
}

Citation for published version (APA):

Spanjers, I. A. E., van Gog, T., Wouters, P., \& van Merrienboer, J. J. G. (2012). Explaining the segmentation effect in learning from animations: The role of pausing and temporal cueing. Computers \& Education, 59(2), 274-280. https://doi.org/10.1016/j.compedu.2011.12.024

Document status and date:

Published: 01/09/2012

DOI:

10.1016/j.compedu.2011.12.024

Document Version:

Publisher's PDF, also known as Version of record

Document license:

Taverne

Please check the document version of this publication:

- A submitted manuscript is the version of the article upon submission and before peer-review. There can be important differences between the submitted version and the official published version of record.

People interested in the research are advised to contact the author for the final version of the publication, or visit the DOI to the publisher's website.

- The final author version and the galley proof are versions of the publication after peer review.

- The final published version features the final layout of the paper including the volume, issue and page numbers.

Link to publication

\footnotetext{
General rights rights.

- You may freely distribute the URL identifying the publication in the public portal. please follow below link for the End User Agreement:

www.umlib.nl/taverne-license

Take down policy

If you believe that this document breaches copyright please contact us at:

repository@maastrichtuniversity.nl

providing details and we will investigate your claim.
}

Copyright and moral rights for the publications made accessible in the public portal are retained by the authors and/or other copyright owners and it is a condition of accessing publications that users recognise and abide by the legal requirements associated with these

- Users may download and print one copy of any publication from the public portal for the purpose of private study or research.

- You may not further distribute the material or use it for any profit-making activity or commercial gain

If the publication is distributed under the terms of Article $25 \mathrm{fa}$ of the Dutch Copyright Act, indicated by the "Taverne" license above, 


\title{
Explaining the segmentation effect in learning from animations: The role of pausing and temporal cueing
}

\author{
Ingrid A.E. Spanjers ${ }^{\mathrm{a}, *}$, Tamara van Gog ${ }^{\mathrm{b}}$, Pieter Wouters ${ }^{\mathrm{c}}$, Jeroen J.G. van Merriënboer ${ }^{\mathrm{a}}$ \\ ${ }^{a}$ Department of Educational Development and Research E' School of Health Professions Education, Maastricht University, P.O. Box 616, 6200 MD Maastricht, The Netherlands \\ ${ }^{\mathrm{b}}$ Institute of Psychology, Erasmus University Rotterdam, P.O. Box 1738, 3000 DR Rotterdam, The Netherlands \\ ${ }^{\mathrm{c}}$ Department of Information and Computing Sciences, Utrecht University, P. O. Box 80.089, 3508 TB Utrecht, The Netherlands
}

\section{A R T I C L E I N F O}

Article history:

Received 17 August 2011

Received in revised form

21 December 2011

Accepted 22 December 2011

\section{Keywords:}

Instructional animations

Segmentation

Cueing

Cognitive load

\begin{abstract}
A B S T R A C T
Segmentation of animations, that is presenting them in pieces rather than as a continuous stream of information, has been shown to have a beneficial effect on cognitive load and learning for novices. Two different explanations of this segmentation effect have been proposed. Firstly, pauses are usually inserted between the segments, which may give learners extra time to perform necessary cognitive processes. Secondly, because segmentation divides animations into meaningful pieces, it provides a form of temporal cueing which may support learners in perceiving the underlying structure of the process or procedure depicted in the animation. This study investigates which of these explanations is the most plausible. Secondary education students $(N=161)$ studied animations on probability calculation, after having been randomly assigned to one of four conditions: non-segmented animations, animations segmented by pauses only, animations segmented by temporarily darkening the screen only, and animations segmented by both pauses and temporarily darkening the screen. The results suggest that both pauses and cues play a role in the segmentation effect, but in a different way.
\end{abstract}

(C) 2011 Elsevier Ltd. All rights reserved.

\section{Introduction}

Dynamic visualizations, such as animations, are increasingly used in instructional materials, for example to illustrate natural processes (e.g., Lin \& Atkinson, 2011), biological processes (e.g., De Koning, Tabbers, Rikers, \& Paas, 2010), mechanical processes (e.g., Boucheix \& Lowe, 2010), and problem-solving procedures (e.g., Van Gog, 2011). However, research has shown that students do not always learn more from animations than from series of static pictures (e.g., Mayer, Hegarty, Mayer, \& Campbell, 2005; Tversky, Morrison, \& Betrancourt, 2002) - with the exception of animations showing human movement procedures (Höffler \& Leutner, 2007; Van Gog, Paas, Marcus, Ayres, \& Sweller, 2009).

It has been proposed that this is a consequence of the cognitive activities required for effectively learning from animations. Learners' working memory is limited in capacity and duration (Baddeley, 2003; Barrouillet \& Camos, 2007). According to cognitive load theory (Sweller, van Merriënboer, \& Paas, 1998), the limitations of working memory should be taken into account in the design of instructional material in order for this material to be effective for learning. Animations are often transient, which imposes high cognitive load on working memory, because the transience of the information presented in animations requires learners to perform cognitive activities which they would not have to perform with static instructional material (cf., Leahy \& Sweller, 2011). As a consequence of transience, information presented at one moment needs to be maintained in working memory for the learner to be able to integrate it with information presented later (Lowe, 1999). Moreover, while maintaining previously presented information, new information keeps streaming which needs to be processed simultaneously (e.g., Ayres \& Paas, 2007). As a result, the total cognitive load imposed by complex animations may be so high that maintaining and processing information needed for learning cannot be adequately coped with in working memory, and learning is hindered.

\footnotetext{
* Corresponding author. Tel.: +3143388 5722; fax: + 31433885779.

E-mail addresses: i.spanjers@maastrichtuniversity.nl (I.A.E. Spanjers), vangog@fsw.eur.nl (T. van Gog), p.j.m.wouters@uu.nl (P. Wouters), j.vanmerrienboer@maastrichtuniversity.nl (J.J.G. van Merriënboer).
} 
Several design measures have been proposed to reduce cognitive load and enhance learning from complex animations. One of them is segmentation, which involves showing animations in pieces rather than as a continuous stream of information (for a review see Spanjers, Van Gog, \& van Merriënboer, 2010). Two alternative, though perhaps not mutually exclusive, processes have been proposed to underlie the beneficial effects of segmentation (Spanjers et al., 2010): pauses between segments give learners extra time to perform necessary cognitive processes (e.g., Mayer \& Moreno, 2003) and by dividing the animation into meaningful pieces, segmentation supports learners in perceiving the underlying structure of the presented information (Boltz, 1992). The present study experimentally investigates which of these two processes provides the most likely explanation of the segmentation effect.

\subsection{The effects of segmentation on learning outcomes and cognitive load}

A number of studies have found positive results of segmentation of animations on learning outcomes and cognitive load for novice learners (e.g., Hasler, Kersten, \& Sweller, 2007; Mayer \& Chandler, 2001; Moreno, 2007; Spanjers, Wouters, van Gog, \& van Merriënboer, 2011). For example, Mayer and Chandler (2001; Experiment 2) found that college students who studied a segmented animation on lightning formation twice, achieved higher scores on a problem-solving transfer test than learners who saw the same animation twice in a non-segmented format. Hasler et al. (2007) had primary school children study instructional material on the determinants of night and day for $10 \mathrm{~min}$ in one of four conditions: (a) a narrated non-segmented animation, (b) a narrated segmented animation, (c) a narrated animation which could be paused by the learner, or (d) the narration of the animation without visual information, segmentation, or a pausing option. They found that children who studied the segmented animation or the animation with the pausing option performed better on the more difficult posttest items than learners in the other two conditions.

In the segmented animations used in the studies by Mayer and Chandler (2001) and Hasler et al. (2007), learners had to click a button after each segment to start the next one. Including learner-control gives learners the possibility to decide when they want to start with the next segment. Furthermore, it may involve learners more actively in the learning process (Wouters, Tabbers, \& Paas, 2007). So, the learner-control implemented in combination with segmentation in these studies might have contributed to the positive effects of segmentation found. Spanjers et al. (2011) studied effects of segmentation on cognitive load and learning without giving participants any control over the animations and still found beneficial effects of animation. Secondary education students studied either non-segmented animations on probability calculation or animations that were segmented through pauses of $2 \mathrm{~s}$, after which the animations continued automatically. During the pauses the screen was slightly darkened. A beneficial effect of segmentation on cognitive load was found for students with low prior knowledge: those studying segmented animations had to invest less mental effort than those studying nonsegmented animations in order to reach the same level of posttest performance. So, positive effects of segmentation can be found without learner-control as well.

\subsection{Possible explanations for the effects of segmentation}

Note that the above mentioned studies reporting positive effects of segmentation differed in whether or not learner-control was present, but all of them involved pausing between the segments. The question is then, whether pausing is critical for a segmentation effect to arise. Spanjers et al. (2010) proposed that there may be two different, though perhaps not mutually exclusive, processes underlying the segmentation effect. Firstly, pausing may be crucial as it reduces the negative effects of transience by giving learners additional time to perform necessary cognitive processing and maintaining activities on the information (e.g., Mayer \& Moreno, 2003), which could enhance learning and reduce cognitive load. According to Barrouillet and Camos (2007) learners execute different cognitive processing and maintaining activities in working memory by sharing attention between these processes in a time-based way. Attention can be given to only one of these processes at a time. To be able to maintain information, learners have to give attention to that information. Similarly, learners need to give attention to processing new information. They do so by quickly and repeatedly switching their attention back and forth between these different cognitive activities. How much of the time learners can give attention to maintaining information, depends on the amount of time they need to give attention to processing. Inserting pauses between segments essentially eliminates the need to attend to new incoming information during that time, allowing learners to devote their attention to maintaining the information shown in the segment for a sufficient amount of time to consolidate it. Without pauses, both maintaining and processing receive less attention, and important information may not be processed or consolidated, which negatively affects learning. Note that this pausing explanation for the segmentation effect is more specific than simply giving learners additional time for the task. According to this explanation, the additional time should be given before learners have forgotten the information. So simply giving learners additional time at the end would not facilitate learning according to this explanation.

Secondly, the beneficial effects of segmentation might not be due so much to pausing as to the fact that segmentation divides animations into meaningful units (cf. Arguel \& Jamet, 2009), which can be seen as a form of temporal cueing. Temporal cueing makes natural boundaries between events in a process or procedure more salient (e.g., Schwan, Garsoffky, \& Hesse, 2000). People naturally tend to identify boundaries between events during perception (Zacks, Speer, Swallow, Braver, \& Reynolds, 2007), and temporal cueing may support learners in this process by reducing the need to identify those boundaries themselves, which may lead to a reduction in cognitive load (cf. Schwan et al., 2000; see also Wouters, Paas, \& van Merriënboer, 2008), which may in turn enhance learning. Temporal cueing may also enhance learning by making learners more aware of the structure of the process or procedure in terms of meaningful events or units (Boltz, 1992; Catrambone, 1998; Florax \& Ploetzner, 2010).

In sum, the positive effects of segmentation on learning outcomes and cognitive load may either be due to pausing, temporal cueing, or a combination of both. Which of those explanations is most plausible, or whether it is their combined effect, cannot be determined based on previous research, as all previous studies involved pauses between segments. 


\subsection{Present study}

The present study aimed to address the question which of the two proposed explanations for the effects of segmentation is the most plausible, using animations on probability calculation (cf. Spanjers et al., 2011). We examined this by investigating the effects of inserting pauses, temporarily darkening the screen slightly at the boundaries of segments, and both, on measures of learning outcomes and cognitive load. Cognitive load was investigated by measuring invested mental effort. Although in the end it are learning outcomes which matter in educational situations, indications that a particular design measure reduces invested mental effort without lowering performance provides some evidence that this design measure supports learning. Design measures that free up working memory resources, allow more resources to be devoted to cognitive processes facilitating learning.

It is hypothesized that when the beneficial effect of segmentation is due to pauses, learning outcomes would be higher, or mental effort invested in learning would be lower in the two conditions with pauses than in the two conditions without pauses. On the other hand, when the beneficial effect of segmentation is due to a temporal cueing effect, learning outcomes would be higher, or mental effort invested in learning would be lower in the two conditions with temporarily darkening of the screen than in the two conditions without temporarily darkening the screen.

\section{Method}

\subsection{Participants and design}

One hundred and seventy one Dutch students in their third year of secondary education volunteered to participate in this study. They were either in general secondary education (which has a total duration of 5 years and gives access to universities of applied sciences) or preuniversity education (which has a total duration of 6 years and gives access to universities of applied sciences as well as academic universities). The students were novices as this study took place prior to probability calculation being taught, which was also indicated by their pretest scores. The pre-university education students can be assumed to have higher general abilities than the general secondary education students, and this was indeed reflected in their posttest scores and mental effort ratings. However, given that they were randomly assigned to conditions and the distribution of different school types over conditions did not differ, this is unlikely to have affected the results. Data from ten students (1-4 from each condition) who presumably did not pay attention to the animations given that they showed no learning at all or even negative difference scores were removed.

This left 161 participants, distributed as follows across one of the four conditions resulting from a $2 \times 2$ design with factors Pausing (Yes vs. No) and Temporal Cueing (Yes vs. No): studying non-segmented animations $(n=42)$, animations segmented by temporarily darkening the screen only $(n=41)$, animations segmented by pauses only $(n=40)$, or animations segmented by a combination of pauses and temporarily darkening the screen $(n=38)$. In Table 1 demographic descriptive statistics for age, gender and school type are presented for each of the conditions.

\subsection{Materials}

\subsubsection{Animations}

A computer-based learning environment developed in Flash CS4 (Adobe, 2008) presented the four animations on probability calculation (see Fig. 1) during the learning phase, preceded by a written introduction. This introduction contained basic information required for learning from the animations about probability calculation, and for students in the three segmented conditions, the introduction also contained condition-specific information. It was stated that the animations were divided into pieces, divided by very short pauses (pauses only condition), divided by very short pauses during which the screen was darkened (pauses + darkening), or divided by temporarily darkening of the screen (darkening only). The darkening only and control condition received additional time corresponding to the duration of the pauses at the end of each animation. They were informed that at the end the screen would be darkened for a short time. The experimental conditions are explained in more detail below.

The text in the animations was narrated by a male voice. The four animations were part of a larger set originally developed and used by Wouters, Paas, and van Merriënboer (2009) and were adapted for this study. The animations demonstrated and explained how to solve probability calculation problems dealing with complex events (i.e., involving more than one individual event). First, two animations on problems involving drawing without replacement were shown, followed by two animations on problems involving drawing with replacement. The animations clarify the meaning of abstract concepts from the problems, such as "drawing with/without replacement" by visualizing them. The first animation for each problem type had a cover story about helmets distributed during a two-day mountain bike trip. The second animation of a problem without replacement was about a mobile phone factory, and the second animation of a problem

Table 1

Descriptive statistics for age, gender and school type per condition.

\begin{tabular}{|c|c|c|c|c|c|c|c|c|c|c|c|c|}
\hline & \multicolumn{3}{|c|}{ Non-segmented } & \multicolumn{3}{|c|}{$\begin{array}{l}\text { Segmented by temporarily } \\
\text { darkening only }\end{array}$} & \multicolumn{3}{|c|}{ Segmented by pauses only } & \multicolumn{3}{|c|}{$\begin{array}{l}\text { Segmented by pauses and } \\
\text { temporarily darkening }\end{array}$} \\
\hline & $n$ & $M$ & sd & $n$ & $M$ & sd & $n$ & $M$ & sd & $n$ & $M$ & sd \\
\hline Age & 42 & 14.81 & 0.55 & 41 & 14.73 & 0.45 & 40 & 14.77 & 0.42 & 38 & 14.84 & 0.55 \\
\hline Female & 22 & & & 24 & & & 19 & & & 17 & & \\
\hline Male & 20 & & & 17 & & & 21 & & & 21 & & \\
\hline Pre-university education & 28 & & & 33 & & & 31 & & & 29 & & \\
\hline General secondary education & 14 & & & 8 & & & 9 & & & 9 & & \\
\hline
\end{tabular}



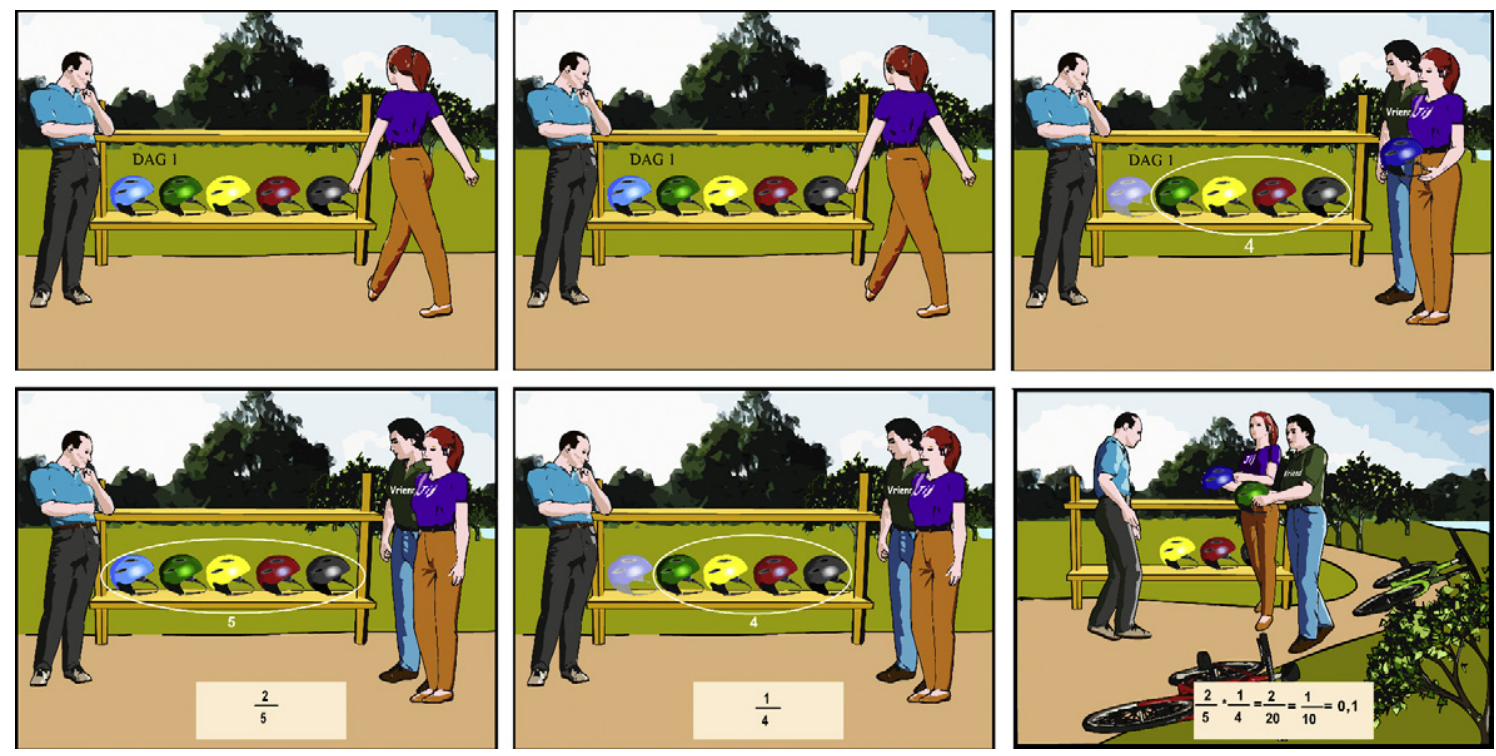

Fig. 1. Series of screen shots from one of the animations (text was spoken).

with replacement was about toys in cereal packs. The duration of each of the animations was a little over 2 min. An example of a cover story of a problem without replacement is: 'Together with your friend, you go on a two-day mountain bike trip. Each day the instructor brings five helmets, which each have a different colour: blue, green, yellow, red and silver. The helmets are distributed randomly and are given back to the instructor at the end of the day. On both days you get a helmet first and your friend second. What is the probability that on the first day, you and your friend will get the blue and green helmet?'. In the remainder of the animation it was demonstrated and explained how this particular probability can be calculated.

The learners were not provided with any control over the animations. In the non-segmented condition, the animations were continuous. In the three segmented conditions the animations were divided into six or seven segments by means of pausing, slightly darkening the screen temporarily, or both. The first segment presented the problem statement (see the example above). The second described that order was not relevant in the problem shown. The third segment discussed whether it was a problem involving drawing with replacement or drawing without replacement. In the fourth and fifth or fourth, fifth, and sixth segments the probabilities of the two or three individual events involved in the problem were determined. In the example above, the probabilities of the individual events are $2 / 5$ and $1 / 4$. In the last segment (i.e., the sixth or seventh segment) the probabilities of the individual events were multiplied in order to calculate the probability of the complex event. For instance, in the example above, the probability of the complex event is $2 / 5 * 1 / 4=2 /$ $20=1 / 10=0.1$.

The animations segmented by pauses only contained pauses of $2 \mathrm{~s}$ between segments, after which the animation continued automatically. In the animations segmented by pauses and temporarily darkening, the screen was slightly darkened during the entire 2-s pause. The slight darkening of the screen was done by overlaying a grey, transparent frame with the same size as the animation on the frame on which the animations paused. Although the screen was slightly darkened, it was still possible to see the frames on which the animations paused. In the animations segmented by temporarily darkening only, the segments were indicated by slightly darkening the screen at the boundaries of segments for half a second (in the same manner as mentioned above), and the animations did not pause while the screen was slightly darkened. To ensure an equal total duration, the animations in the two conditions without pauses contained a slightly darkened screen at the end of the animations for $10 \mathrm{~s}$ (in case of 5 pauses in the other conditions; i.e., animations with 6 segments) or $12 \mathrm{~s}$ (in case of 6 pauses in the other conditions; i.e., animations with 7 segments).

\subsubsection{Pretest and posttest}

The paper-and-pencil pretest and posttest consisted of different, but isomorphic items. The four items were all probability calculation problems with the same structural features, but different cover stories than the problems solved in the animations. The order of problems in terms of drawing with and without replacement was different for the two tests. An example of a problem is 'You and your friend work at the supermarket. Today eight persons are working. Two of them will need to clean the canteen, and you will draw lots to determine who that will be. You predict that you and your friend will have to do this task. What is the probability that your prediction comes true?'

Two points could be obtained for each test problem when the correct outcome was calculated using the correct formula (i.e., belonging to that problem type). One point was given if the correct formula was used, but the wrong answer was given. No points were assigned when the wrong formula was used, even when a correct outcome was reported (which sometimes happened due to calculation errors). The maximum score on both the pretest and the posttest was eight points.

\subsubsection{Mental effort rating scales}

Students were asked to rate how much mental effort they invested in studying each animation on a nine-point rating scale ranging from (1) very, very low mental effort to (9) very, very high mental effort (Paas, 1992). These rating scales were presented on paper. A mean score was calculated across the four animations. 


\subsection{Procedure}

The experiment took place in computer rooms at participants' schools in group sessions with a duration of approximately $1 \mathrm{~h}$, with all conditions being present in each session. First, participants completed the pretest. Then they read the introduction to the experiment on the computer screen ( $4 \mathrm{~min}$ ). Subsequently, they studied the four animations, using head phones to listen to the narration. After each animation, they rated the mental effort invested in studying the animation. Finally, they completed the posttest. After completing the posttest students were thanked for their participation.

\section{Results}

Descriptive statistics for pretest and posttest scores and mental effort invested in learning from the animations are shown in Table 2. On the tests, missing answers were scored as errors. The significance level for the comparisons was set at 0.05 , and eta-squared is reported as a measure of effect size, with 0.01 indicating a small, 0.06 a moderate and 0.14 a large effect. The conditions did not differ in pretest scores, $F(3,157)=1.21$, MSE $=1.02, p=0.31, \eta_{p}^{2}=0.02$.

A 2-by-2 ANOVA revealed a main effect of Pausing on posttest scores: participants studying animations with pauses $(M=6.46$, sd $=1.79)$ performed significantly better on the posttest than participants studying animations without pauses $(M=5.80, s d=2.16), F(1,157)=4.39$, $p=0.04$, MSE $=3.92, \eta_{p}^{2}=0.03$. There was no significant main effect of Cueing, $F(1,157)=0.49, p=0.48, \eta_{p}^{2}=0.003$ nor an interaction effect between Cueing and Pausing, $F(1,157)=2.85, p=0.09, \eta_{p}^{2}=0.02$.

A 2-by-2 ANOVA on mental effort invested during animation study showed a significant main effect of Cueing: learning from animations with cues $(M=2.19, \mathrm{sd}=1.05)$ required significantly less investment of mental effort than learning from animations without cues $(M=2.73$, $\mathrm{sd}=1.70), F(1,157)=5.67, p=0.02, \mathrm{MSE}=2.01, \eta_{p}^{2}=0.03$. There was no significant main effect of Pausing $F(1,157)=2.33, p=0.13, \eta_{p}^{2}=0.01$, nor a significant interaction effect $F(1,157)=0.33, p=0.56, \eta_{p}^{2}=0.002$.

\section{Discussion}

Previous studies that showed benefits of segmentation of dynamic visualizations on learning outcomes and cognitive load all included pauses between segments (e.g., Hasler et al., 2007; Mayer \& Chandler, 2001; Moreno, 2007; Spanjers et al., 2011).Therefore, our study aimed to investigate whether pauses play a crucial role in the segmentation effect, as they provide learners with additional time for necessary cognitive activities (e.g., Mayer \& Moreno, 2003) or whether the effect is caused by temporal cues that make the underlying structure of the information shown clearer (Boltz, 1992). The results seem to suggest that both pausing and temporal cueing contribute to the effect, though in a different manner.

First of all, results showed that the insertion of pauses between segments had a positive effect on posttest achievement without affecting mental effort invested in studying the animations. These results provide evidence for the pausing explanation of the segmentation effect, which states that segmentation facilitates learning, because pauses give learners additional time during animation study to perform cognitive processes necessary for learning. It should be noted that learners studying animations without pauses were given additional time for information processing at the end of each animation, although we cannot be sure whether they actually used this time for on-task behaviour. However, the positive effect of the segmentation by pauses is not likely to be due to simply being given additional time to process each animation. Rather, some time needs to be provided after each segment (i.e., a small unit of information), to enable learners to maintain the information without having to attend to new incoming information.

Secondly, it was found that the insertion of cues in the form of slightly darkening the screen had a positive effect on mental effort investment during animation study: less effort was required for learning from the animations when cues were present, without affecting posttest achievement. These results provide evidence for the temporal cueing explanation, which states that segmentation influences learning outcomes or mental effort invested in learning positively, because it makes natural event boundaries more salient, reducing the need to search for those boundaries, and thereby reducing cognitive load.

Note that we cannot completely disentangle the two explanations, because the pauses also inherently provide cues regarding the structure of the material. We may conclude, however, that both segmentation by cueing in the form of temporarily darkening the screen and by pausing have a positive effect on learning outcomes or cognitive load. Although this suggest that both processes are underlying the segmentation effect, future research could attempt to further distinguish between the two explanations by comparing the effects of segmenting animations by means of pauses in meaningful and random segments. If temporal cueing plays a role, negative effects would arise in

Table 2

Descriptive statistics for pretest and posttest performance and mental effort during pretest, posttest and animations study per condition.

\begin{tabular}{|c|c|c|c|c|c|c|c|c|c|c|c|c|}
\hline & \multicolumn{3}{|c|}{ Non-segmented } & \multicolumn{3}{|c|}{$\begin{array}{l}\text { Segmented by temporarily } \\
\text { darkening only }\end{array}$} & \multicolumn{3}{|c|}{ Segmented by pauses only } & \multicolumn{3}{|c|}{$\begin{array}{l}\text { Segmented by pauses and } \\
\text { temporarily darkening }\end{array}$} \\
\hline & $n$ & $M$ & sd & $n$ & $M$ & sd & $n$ & $M$ & sd & $n$ & $M$ & sd \\
\hline \multicolumn{13}{|l|}{ Pretest $(0-8)$} \\
\hline Scores & 42 & 0.29 & 0.71 & 41 & 0.51 & 0.87 & 40 & 0.70 & 1.24 & 38 & 0.42 & 1.15 \\
\hline \multicolumn{13}{|l|}{ Learning } \\
\hline Mental effort (1-9) & 42 & 2.63 & 1.39 & 41 & 1.96 & 0.96 & 40 & 2.84 & 1.99 & 38 & 2.43 & 1.10 \\
\hline \multicolumn{13}{|l|}{ Posttest (0-8) } \\
\hline Scores & 42 & 5.64 & 2.27 & 41 & 5.95 & 2.05 & 40 & 6.82 & 1.38 & 38 & 6.08 & 2.10 \\
\hline
\end{tabular}


the randomly segmented condition. If it is only pausing that is important because it gives learners additional time to perform cognitive processes, than it should not make a difference whether segments are meaningful or random.

Although it would be interesting to replicate this study with animations on other topics than math, we feel our results might generalize to other animation content because the segmentation effect has also been demonstrated with dynamic visualizations on natural processes (Hasler et al., 2007; Mayer \& Chandler, 2001) and teaching skills (Moreno, 2007) in which pauses were included between segments.

A potential limitation of this study is that the posttest only contained one type of questions. Consequently, we did not assess whether students differed in, for example, the amount of conceptual knowledge they gained from the animations; however, conceptual knowledge is needed to be able to identify which solution procedure would be required in the items we used. The measure used to assess mental effort invested was a one item subjective rating scale. Although this measure is used often in educational research (Paas, Tuovinen, Tabbers, \& Van Gerven, 2003), and is sensitive to variations in cognitive load, especially when repeatedly applied as in this study (see Ayres, 2006; Paas et al., 2003), it is a measure of overall load that does not allow one to investigate fluctuations in cognitive load during animation study. Using objective and online measures in future research, such as secondary tasks (Brünken, Plass, \& Leutner, 2003) or psychophysiological measures such as eye tracking (Van Gerven, Paas, van Merriënboer, \& Schmidt, 2004) or EEG (Antonenko, Paas, Grabner, \& van Gog, 2010) could provide more insight into for example the processing activities that occur around segment boundaries during animation study. It might also be interesting to obtain more subjective process data, for example using verbal reports to uncover cognitive processes in response to animations with different types of segmentation. The most widely used verbal reporting method, thinking aloud (Ericsson \& Simon, 1993), may not be usable though, as thinking aloud when studying the animation would interfere with listening to the narrations. Cued retrospective reporting (Van Gog, Paas, Van Merriënboer, \& Witte, 2005) might provide an alternative. This method would request participants to retrospectively verbalize their thoughts during animation study supported by a replay of the animations with their own eye movements superimposed on them. Previous studies on learning from animations and videos have already used this method (De Koning et al., 2010; Jarodzka, Scheiter, Gerjets, \& van Gog, 2010).

In sum, although further research is needed to further disentangle the two explanations, this study suggests that they both play a role in attaining a segmentation effect with transient dynamic visualizations, which is a useful finding for designers of instructional animations.

\section{Acknowledgments}

This work was funded by the Netherlands Organization for Scientific Research (NWO; project \# 400-07-017).

\section{References}

Adobe. (2008). Flash CS4тм [Computer software]. San Jose, CA: Adobe.

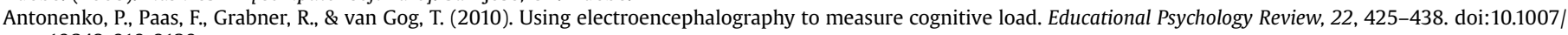
s10648-010-9130-y.

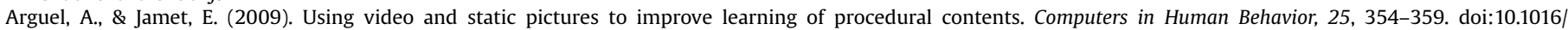
j.chb.2008.12.014.

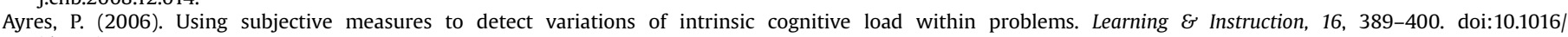
j.learninstruc.2006.09.001.

Ayres, P., \& Paas, F. (2007). Making instructional animations more effective: a cognitive load approach. Applied Cognitive Psychology, 21, 695-700. doi:10.1002/acp.1343.

Baddeley, A. (2003). Working memory: looking back and looking forward. Nature Reviews Neuroscience, 4, 829-839. doi:10.1038/nrn1201.

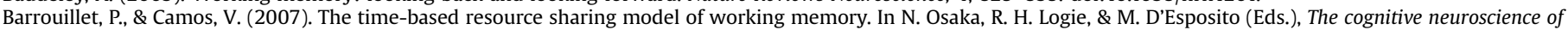
working memory (pp. 59-80). Oxford, England: Oxford University Press.

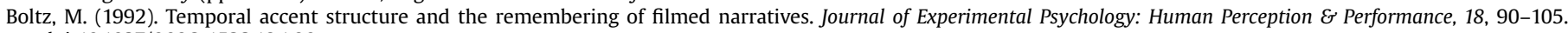
doi:10.1037/0096-1523.18.1.90.

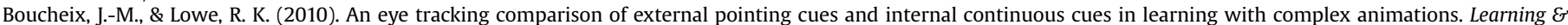
Instruction, 20,123-135. doi:10.1016/j.learninstruc.2009.02.015.

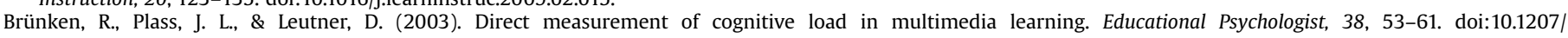
S15326985EP3801_7.

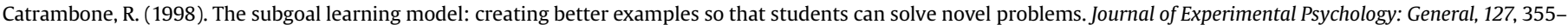
376. doi:10.1037//0278-7393.22.4.1020.

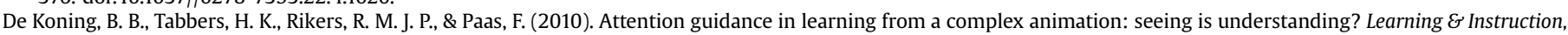
20, 111-122. doi:10.1016/j.learninstruc.2009.02.010.

Ericsson, K. A., \& Simon, H. A. (1993). Protocol analysis: Verbal reports as data (Rev. ed.). Cambridge, MA: MIT Press.

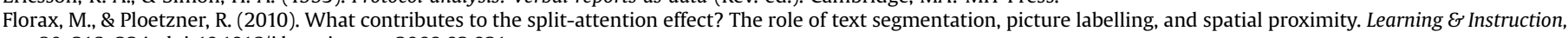
20, 216-224. doi:10.1016/j.learninstruc.2009.02.021.

Hasler, B. S., Kersten, B., \& Sweller, J. (2007). Learner control, cognitive load and instructional animation. Applied Cognitive Psychology, 21, 713-729. doi:10.1002/acp.1345.

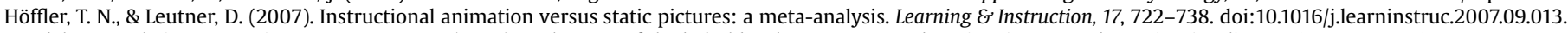

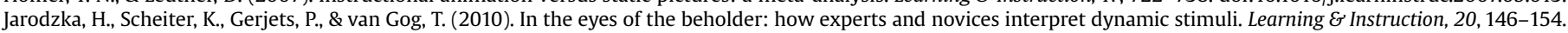
doi:10.1016/j.learninstruc.2009.02.019.

Leahy, W., \& Sweller, J. (2011). Cognitive load theory, modality of presentation and the transient information effect. Applied Cognitive Psychology, $25,943-951$.

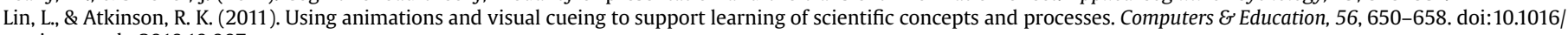
j.compedu.2010.10.007.

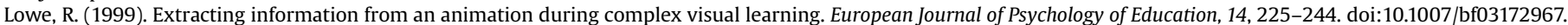

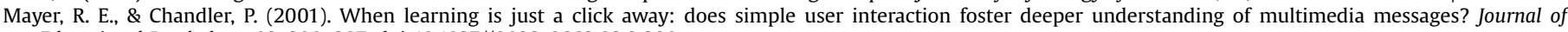
Educational Psychology, 93, 390-397. doi:10.1037//0022-0663.93.2.390.

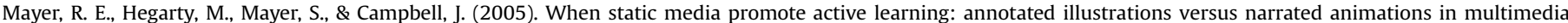
instruction. Journal of Experimental Psychology: Applied, 11, 256-265. doi:10.1037/1076-898X.11.4.256.

Mayer, R. E., \& Moreno, R. (2003). Nine ways to reduce cognitive load in multimedia learning. Educational Psychologist, 38, 43-52. doi:10.1207/S15326985EP3801_6.

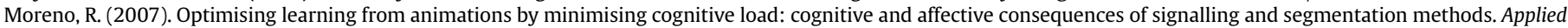
Cognitive Psychology, 21, 765-781. doi:10.1002/acp.1348.

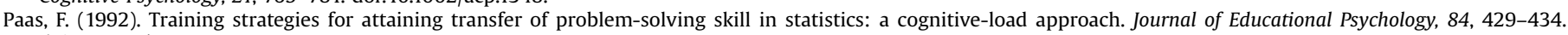
doi:10.1037/0022-0663.84.4.429.

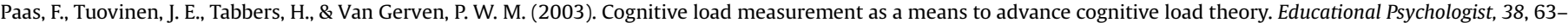
71. doi:10.1207/S15326985EP3801_8.

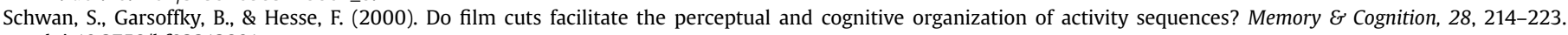
doi:10.3758/bf03213801. 


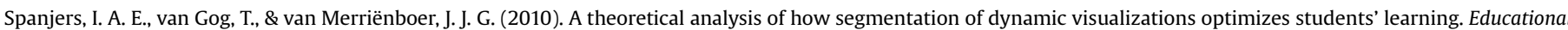
Psychology Review, 22, 411-423. doi:10.1007/s10648-010-9135-6.

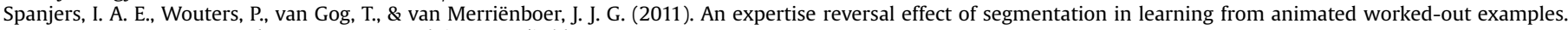
Computers in Human Behavior, 27, 46-52. doi:10.1016/j.chb.2010.05.011.

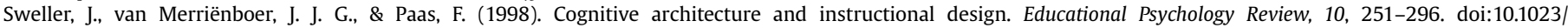
a:1022193728205.

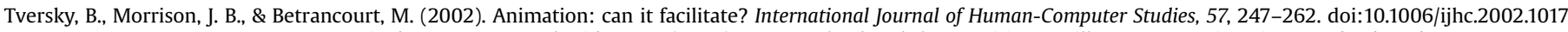

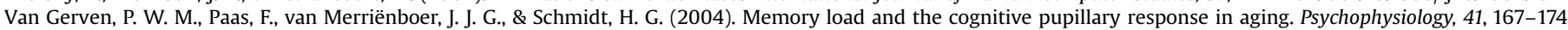
doi:10.1111/j.1469-8986.2003.00148.x.

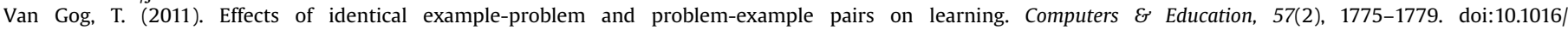
j.compedu.2011.03.019.

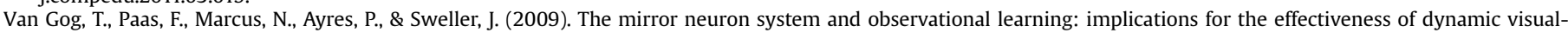
izations. Educational Psychology Review, 21, 21-30. doi:10.1007/s10648-008-9094-3.

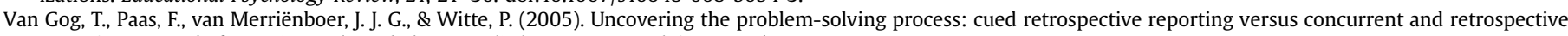
reporting. Journal of Experimental Psychology: Applied, 11, 237-244. doi:10.1037/1076-898X.11.4.237.

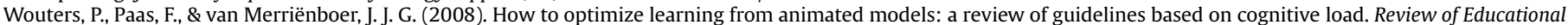
Research, 78, 645-675. doi:10.3102/0034654308320320.

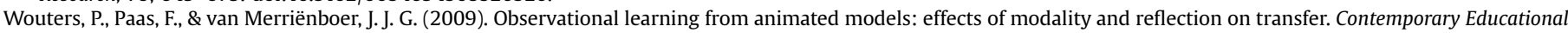
Psychology, 34, 1-8. doi:10.1016/j.cedpsych.2008.03.001.

Wouters, P., Tabbers, H. K., \& Paas, F. (2007). Interactivity in video-based models. Educational Psychology Review, 19, 327-342. doi:10.1007/s10648-007-9045-4.

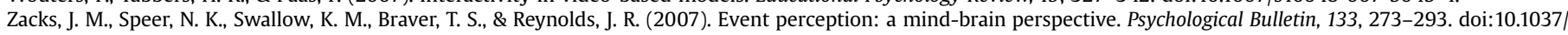
0033-2909.133.2.273. 